\title{
Myocardial ischemia induced by three-vessel coronary-cameral fistulas
}

\author{
Mustafa Oylumlu, Abdulkadir Yildiz, Murat Yuksel, Abdurrahman Akyuz \\ Department of Cardiology, School of Medicine, Dicle University, Diyarbakir, Turkey
}

Postep Kardiol Inter 2014; 10, 2 (36): 135-137

DOI: 10.5114 /pwki.2014.43524

\begin{abstract}
A bstract
Coronary-cameral fistula is a scarce clinical entity, which is defined as an anomalous communication between any epicardial coronary artery and cardiac chambers or large vessels. We aimed to present a case of multiple coronary-cameral fistulas causing myocardial ischemia.
\end{abstract}

Key words: coronary anomaly, coronary-cameral fistulas, ischemia.

\section{Introduction}

Coronary-cameral fistulas (CCF) are abnormal communications between a coronary artery and a heart chamber, which are reported in $0.1 \%$ of patients undergoing diagnostic coronary angiography [1]. The patients are usually asymptomatic so these fistulas are usually detected incidentally during coronary angiography. However, if fistulas are widespread they may cause ischemia and symptoms related to volume overload. The involvement of all three major coronary arteries in fistula formation is even less frequent.

\section{Case report}

A 75-year-old female patient was referred to the cardiology department with a diagnosis of acute coronary syndrome. She had chest pain and palpitations over the past several months. Besides age she had no additional risk factors for coronary artery disease. Electrocardiogram showed normal sinus rhythm and symmetric $\mathrm{T}$ wave negativity on the anterolateral leads (Figure 1). Cardiac enzyme levels and troponin levels were normal. Physical examination was unremarkable. Transthoracic echocardiography revealed slight left atrial enlargement and mild mitral and aortic regurgitation with normal left ventricular systolic function. We performed dobutamine stress echocardiography since the patient could not tolerate exercise, which revealed ischemia at the anterior and lateral wall regions of the left ventricle.
Coronary angiography revealed normal epicardial coronaries with a widespread passage of the contrast agent from the left anterior descending, circumflex and right coronary arteries to the left ventricular cavity (Figures 2 and 3). The diagnosis of multiple coronary-cameral fistulas (CCF) was considered and the patient was treated conservatively with metoprolol.

\section{Discussion}

Coronary-cameral fistula is a scarce clinical entity, which is defined as an anomalous communication between any epicardial coronary artery and cardiac chambers or large vessels. Coronary artery fistulas are observed at an incidence of $0.1 \%$ [1]. Major sites of fistula origin are the right coronary artery, left coronary artery, and both coronary arteries simultaneously. Low-pressure structures are the most common sites of CCF drainage. Major termination sites are the right ventricle, right atrium, pulmonary arteries and less frequently the left atrium and left ventricle [2]. Coronary angiography is the gold standard for the diagnosis of CCF. It can reveal the size, number, origin and termination site of the fistulas.

Most CCF are detected incidentally during coronary angiography. Most patients are asymptomatic; however, it may lead to various symptoms [3]. Symptoms depend on the size of the fistula and the severity of left-to-right shunting. The most common clinical presentation is a continuous heart murmur. Other manifestations are dyspnea, congestive heart failure, and chest pain. Less

\section{Corresponding author:}

Mustafa Oylumlu MD, Department of Cardiology, School of Medicine, Dicle University, 21280 Diyarbakir, Turkey, phone: +90 04122488001 , e-mail: dr.oylumlu@yahoo.com

Received: 2.08.2013, accepted: 10.10.2013. 


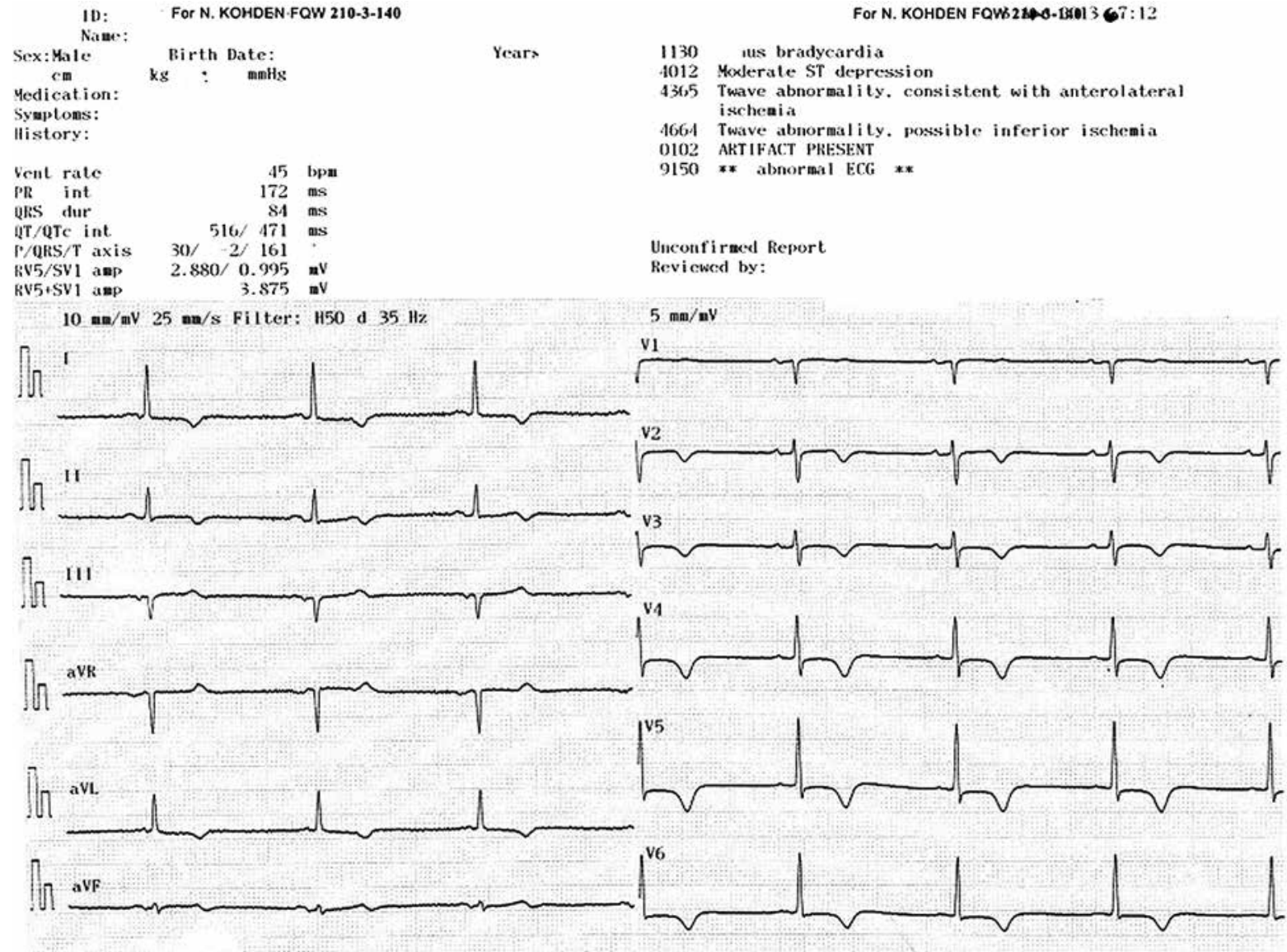

Figure 1. Electrocardiography revealed ischemic T-wave changes on the anterior and lateral leads
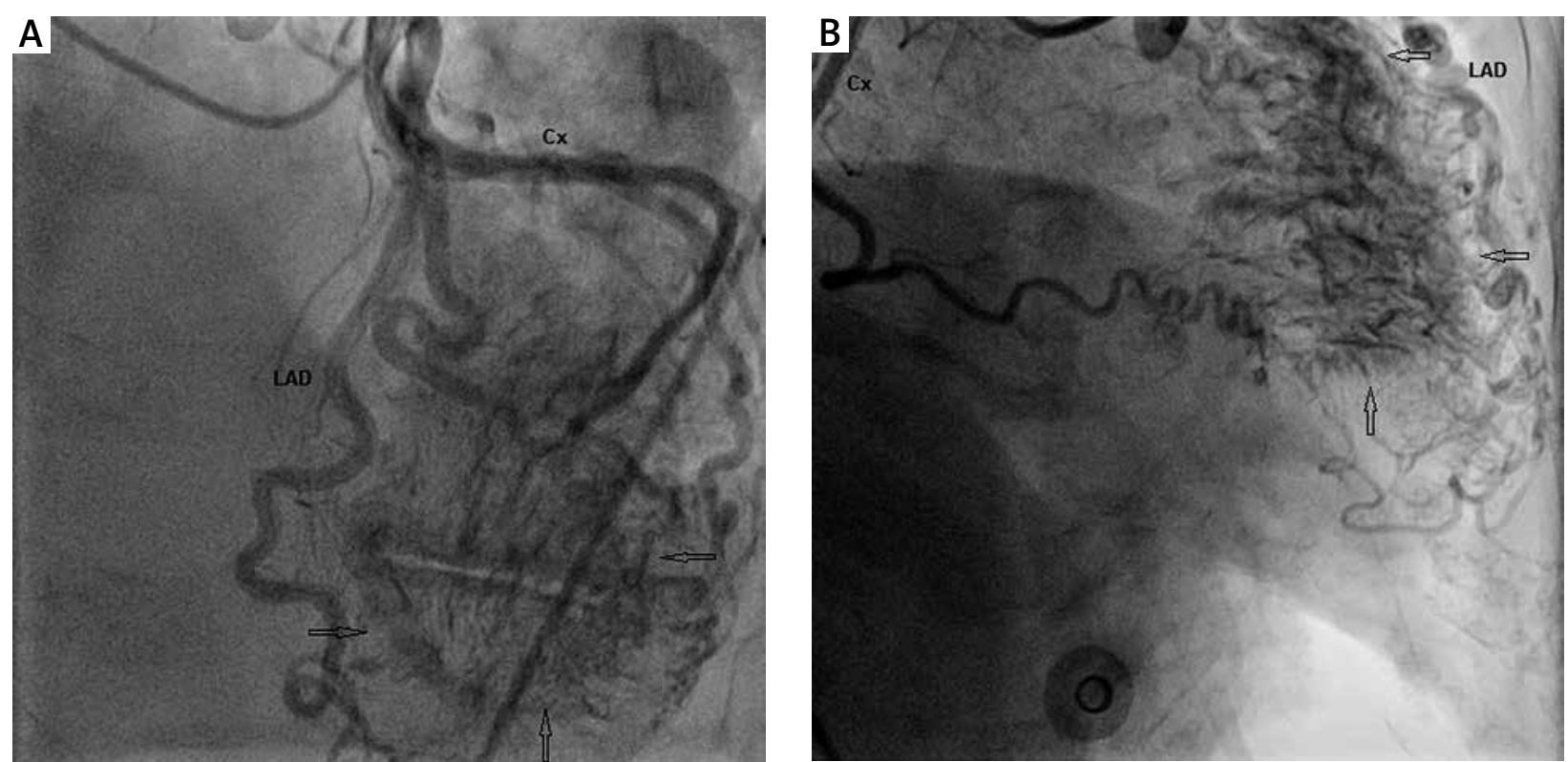

Figure 2. A - Anterior-posterior cranial view showing the coronary-cameral fistulas between left anterior descending artery (LAD), circumflex artery and left ventricle (arrows). B - Right anterior oblique view showing the coronary-cameral fistulas between LAD, circumflex artery and left ventricle (arrows) 

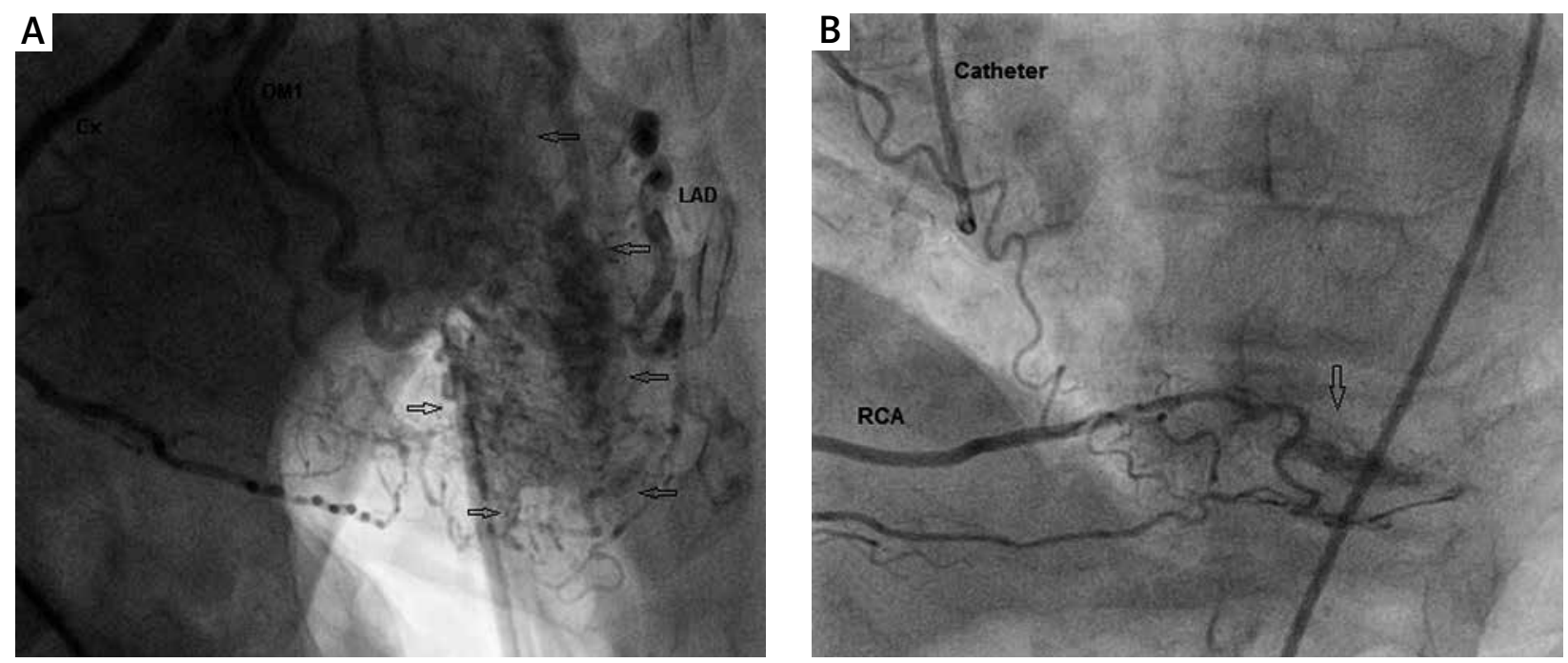

Figure 3. A - Right anterior oblique view showing the coronary-cameral fistulas between LAD, circumflex artery and left ventricle (arrows). B - Left anterior oblique cranial view showing the coronary-cameral fistulas between right coronary artery and left ventricle (arrows)

common presentations include arrhythmia, stroke, endocarditis and myocardial infarction [4].

The natural history of CCF is largely unknown. Although the majority of adults remain asymptomatic, large left-to-right shunts may promote the development of mild-to-moderate pulmonary hypertension due to volume overload [2]. Independent of fistula size, bacterial endocarditis has been reported in patients with CCF [5].

Because of the relatively benign nature of this disease, treatment is usually required only for large leftto-right shunt or progressively increasing shunt (Qp/Qs: 1.5), congestive heart failure, left ventricular dysfunction or overload, myocardial ischemia, and endocarditis. The treatment options are surgical repair and transcatheter closure, which have similar results regarding effectiveness, morbidity, and mortality [6].

Because of the multiplicity and small caliber of the fistulas, neither treatment option was feasible in our case. $\beta$-Blockers may be preferred in cases of small multiple fistulas causing myocardial ischemia.

\section{References}

1. Vavuranakis M, Bush CA, Boudoulas H. Coronary artery fistulas in adults: incidence, angiographic characteristics, natural history. Cathet Cardiovasc Diagn 1995; 35: 116-20.

2. Hobbs RE, Millit HD, Raghaven PV, et al. Coronary artery fistulae: a 10-year review. Cleve Clin Q 1982; 49: 191-7.

3. Brooks CH, Bates PD. Coronary artery-left ventricular fistula with angina pectoris. Am Heart J 1983; 106: 404-6.

4. Said SA, Lam J, van der Werf T. Solitary coronary artery fistulas: a congenital anomaly in children and adults. A contemporary review. Congenit Heart Dis 2006; 1: 63-76.
5. Stansel HC Jr, Fenn JE. Coronary arteriovenous fistula between the left coronary artery and persistent left superior vena cava complicated by bacterial endocarditis. Ann Surg 1964; 160: 292-6.

6. Mavroudis C, Backer CL, Rocchini AP, et al. Coronary artery fistulas in infants and children: a surgical review and discussion of coil embolization. Ann Thorac Surg 1997; 63: 1235-42. 